\title{
Palladium-Catalyzed Hydroarylation of Homopropargyl Iodoindoles with Concurrent Alkyl and Iodonium Migrations
}

\author{
Irene Martín, ${ }^{\mathrm{a}}$ Cristina Aragoncillo, ${ }^{\mathrm{b} *}$ and Pedro Almendros ${ }^{\mathrm{a} *}$ \\ a Instituto de Química Orgánica General, IQOG, CSIC, Juan de la Cierva 3, 28006-Madrid, Spain \\ E-mail: palmendros@iqog.csic.es \\ b Grupo de Lactamas y Heterociclos Bioactivos, Departamento de Química Orgánica, Unidad Asociada al CSIC, \\ Facultad de Química, Universidad Complutense de Madrid, 28040-Madrid, Spain \\ E-mail: caragoncillo@quim.ucm.es
}

Received: ((will be filled in by the editorial staff))

Supporting information for this article is available on the WWW under http://dx.doi.org/10.1002/adsc.201\#\#\#\#\#.((Please delete if not appropriate))

\begin{abstract}
A selective palladium-catalyzed C(sp) arylation/carbocyclization/iodonium migration reaction sequence has been accomplished. Novel 2-iodo-1-aryl-9H-carbazoles are now easily available. As this result is contrary to the selectivity observed using gold catalysis, the formation of 2-iodo-carbazoles is noticeable, suggesting a metal-controlled cyclization through chemo- and regioselective 1,2-alkyl migration and 1,4-iodonium migration.
\end{abstract}

Keywords: carbazole; cyclization; homogeneous catalysis; iodonium migration; palladium

The carbazole core is a fundamental tvpe of nucleus due to the widespread occurrence of this heterocvcle in bioactive compounds. advanced materials. and natural products. ${ }^{[1]}$ Because the relevance of this framework, there is still a demand for the development of straightforward and efficient synthesis of the functionalized carbazole motif.

On the other hand. haloalkenes and haloarenes are widelv used in metal-catalvzed cross-coupling reactions. ${ }^{[2]}$ However. the halogenated functionalitv is normally expelled. which diminished the svnthetic utilitv of the obtained products. To surpass this limitation. the reintegration of the halogen atom into the target molecule has evolve into a challenging yet interesting issue. ${ }^{[3]}$ Hashmi et al. have described the preparation of disubstituted alkynes from terminal (indol-2-yl)butynols under Sonogashira conditions and its gold-catalyzed cyclization (Scheme 1a). ${ }^{[4 \mathrm{a}]}$ In the same year Ma reported the synthesis of carbazoles via $\mathrm{Au}(\mathrm{III})$-catalyzed cyclization of 1-(indol-2-vl)-3-alkvn-1-ols. ${ }^{[4 b]}$ while we have recently described the gold- catalvzed intramolecular 1.3-iodine transfer reaction in (3-iodoindol-2-vl)butvnols for the synthesis of polyfunctionalized carbazoles (Scheme 1b). ${ }^{[5]}$ Taking into account that the above iodine migration as well as the direct iodination of the carbazole nucleus occurred at the $\mathrm{C} 3$ position, ${ }^{[6]}$ the discovery of new protocols for the controlled preparation of iodinated carbazoles at different positions is challenging. Notwithstanding the significant progress attained in this area, the reported protocols suffer from drawbacks such as the necessity of preparation of sophisticated precursors. Our aim was the adoption of Pd-catalytic conditions in a tandem Sonogashira-carbocyclization process for the straightforward preparation of iodocarbazoles in a more efficient manner. Herein, we report an unprecedented palladium-catalyzed synthesis of 2-iodo-1-aryl-9H-carbazoles coupled to a selectivity switch in comparison with gold catalysis $^{[7]}$ (Scheme 1c).

Previous work

(a)
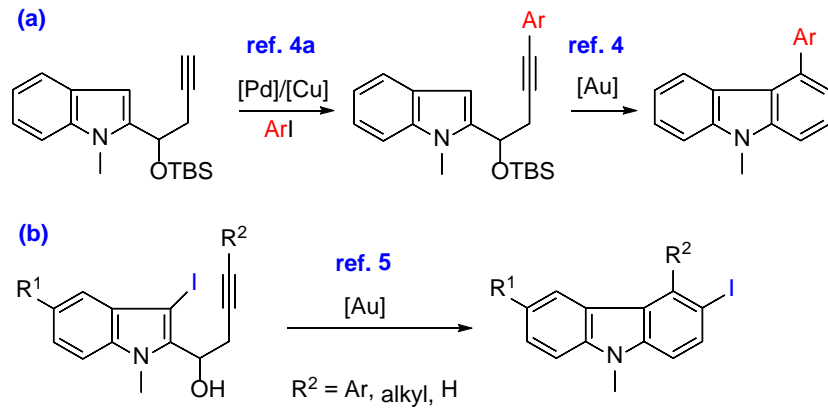

Current work (c)

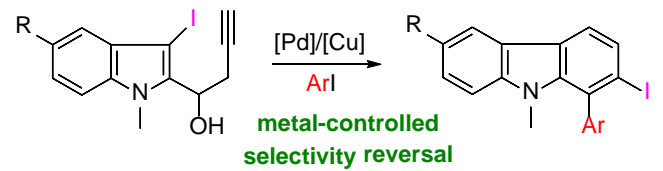


Scheme 1. Previous studies and current design for the metal-catalyzed hydroarylation reactions of C2-alkynetethered iodoindoles.

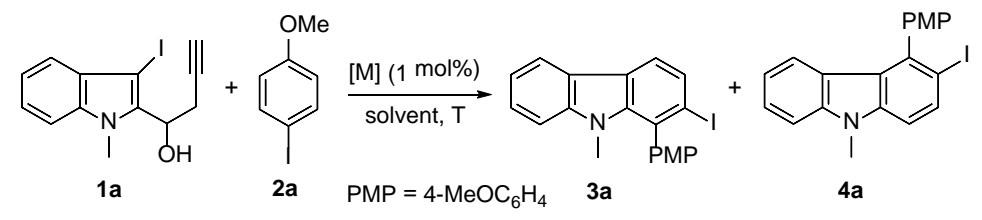

Table 1. Reaction of 1-(3-iodoindol-2-yl)but-3-yn-1-ol 1a with iodoarene 2a under modified metal-catalyzed conditions.

\begin{tabular}{|c|c|c|c|c|c|c|}
\hline entry & catalyst & base & solvent & $\mathrm{T}\left({ }^{\circ} \mathrm{C}\right)$ & time $(\mathrm{h})^{a}$ & yield (\%) ${ }^{b}$ \\
\hline 1 & $\mathrm{Pd}(\mathrm{OAc})_{2}$ & $\mathrm{~K}_{2} \mathrm{CO}_{3}$ & ethanol & 80 & 1.5 & $3 \mathbf{a}(0) / 4 a(0)$ \\
\hline 2 & $\mathrm{Pd}(\mathrm{OAc})_{2}$ & DABCO & acetonitrile & 40 & 2 & 3a (12)/4a (2) \\
\hline 3 & $\mathrm{Pd}(\mathrm{OAc})_{2} / \mathrm{CuI}$ & $\mathrm{Et}_{3} \mathrm{~N}$ & $\mathrm{Et}_{3} \mathrm{~N}$ & 40 & 2 & 3a (15)/4a (2) \\
\hline 4 & $\mathrm{Pd}\left(\mathrm{PPh}_{3}\right)_{2} \mathrm{Cl}_{2} / \mathrm{CuI}$ & $\mathrm{Et}_{3} \mathrm{~N}$ & $\mathrm{Et}_{3} \mathrm{~N}$ & 40 & 2 & 3a (44)/4a (5) \\
\hline 5 & $\mathrm{Pd}\left(\mathrm{PPh}_{3}\right)_{2} \mathrm{Cl}_{2} / \mathrm{CuI}$ & DABCO & acetonitrile & 40 & 2 & 3a (35)/4a (3) \\
\hline 6 & $\mathrm{Pd}\left(\mathrm{PPh}_{3}\right)_{2} \mathrm{Cl}_{2} / \mathrm{CuI}$ & $\mathrm{Na}_{2} \mathrm{CO}_{3}$ & DMF & 60 & 2 & 3a (21)/4a (2) \\
\hline 7 & $\mathrm{CuI}$ & $\mathrm{Et}_{3} \mathrm{~N}$ & $\mathrm{Et}_{3} \mathrm{~N}$ & 40 & 2 & 3a (0)/4a (0) \\
\hline 8 & $\mathrm{NiI}_{2}\left(\mathrm{PPh}_{3}\right)_{2} / \mathrm{Mn}$ & - & toluene & 80 & 2 & $3 \mathbf{a}(5) / 4 \mathbf{a}(1)^{c}$ \\
\hline
\end{tabular}

a) Reaction progress was followed by TLC. ${ }^{b)}$ Yield of pure, isolated product with correct analytical and spectral data. ${ }^{c} 40 \%$ of non-iodinated 1a was recovered.

Initiallv. the reaction between 1-(3-iodo-1methvl-1H-indol-2-vl)but-3-vn-1-ol 1 a and 1iodo-4-methoxvbenzene 2a was evaluated. To our satisfaction. when the process was catalyzed by a palladium comblex. the 1-aryl-2-iodo-9Hcarbazole 3a was obtained as the dominating product (Table 1). Worthv of note. carbazole $\mathbf{3 a}$ is an unanticidated product which should arise from a Sonogashira/skeletal reorganization seauence. The formation of 3a contrasts with the previouslv reported gold-catalvzed seauence $\mathrm{e}^{[5]}$ and is a nice example of diverting selectivitv through the iudicious election of metal catalvst. Taking into account the role of bases and ligands in Pdcatalvzed reactions. the optimizations of the reaction conditions was performed by the use of different palladium-based salts, bases, and solvents. The experiments in Table 1 disclosed that $\mathrm{Pd}\left(\mathrm{PPh}_{3}\right)_{2} \mathrm{Cl}$, as the palladium source and $\mathrm{CuI}$ as co-catalvst led to the best result. and carbazole 3a was achieved in 44\% vield (Table 1. entrv 4). Control experiments revealed that the cross-

coupling/carbocvclization/rearrangement/iodine migration seauence was not detected in the absence of the palladium complex (Table 1, entry 7 ). The copper co-catalyst is necessary for the reaction to proceed because in the absence of the copper salt little or none carbazole product was obtained. Organic bases such as $\mathrm{Et}_{3} \mathrm{~N}$ and DABCO performed better than inorganic bases
( $\mathrm{Na}{ }_{2} \mathrm{CO}_{3}$ and $\mathrm{K}_{2} \mathrm{CO}_{3}$ ). Solvent screening showed that the use of $\mathrm{Et}_{3} \mathrm{~N}$ both as base as well as solvent was verv effective. Nickel salts provided a poor outcome (Table 1. entrv 8). 1-Iodo-4methoxvbenzene 2a could be substituted bv 1bromo-4-methoxvbenzene. but carbazole 3a was obtained with a diminished vield.

Next. the electronic effects imparted bv the presence of different substituents at the iodoarene were evaluated using iodoalkvnol 1a as the model substrate. From results in Scheme 2. it became evident that the electronic nature of the iodoarene partner could modulate the selectivitv outcome. The presence of electron-donating substituents such as methoxv on the benzene ring have a marked directing effect of the formed iodocarbazole products, with the main product being the 1-arvl-2-iodo-9H-carbazole 3 isomer. When iodoarenes $\mathbf{2}$ bearing an electronwithdrawing substituent such as nitro on the benzene ring were used. the selectivitv was reverted in favour of the 4-arvl-3-iodo-9Hcarbazole counterpart 4. Afterwards. the generalitv of this cross-coupling/skeletal reorganization sequence was studied using heteroarvl iodides such as 2-iodothiophene and 3iodo- $1 \mathrm{H}$-indole-2-carbaldehvdes. When the ontimized reaction conditions were abDlied to these heteroarvl iodides and iodoalkvnol $\mathbf{1 a}$. chromatographicallv sedarable mixtures of carbazoles $\mathbf{3}$ and $\mathbf{4}$ were obtained. In case whereas 
the competing reaction could not be fully suppressed. the practical application of this method in organic synthesis was obvious because both isomeric carbazoles could be easily separated by bench column chromatography.

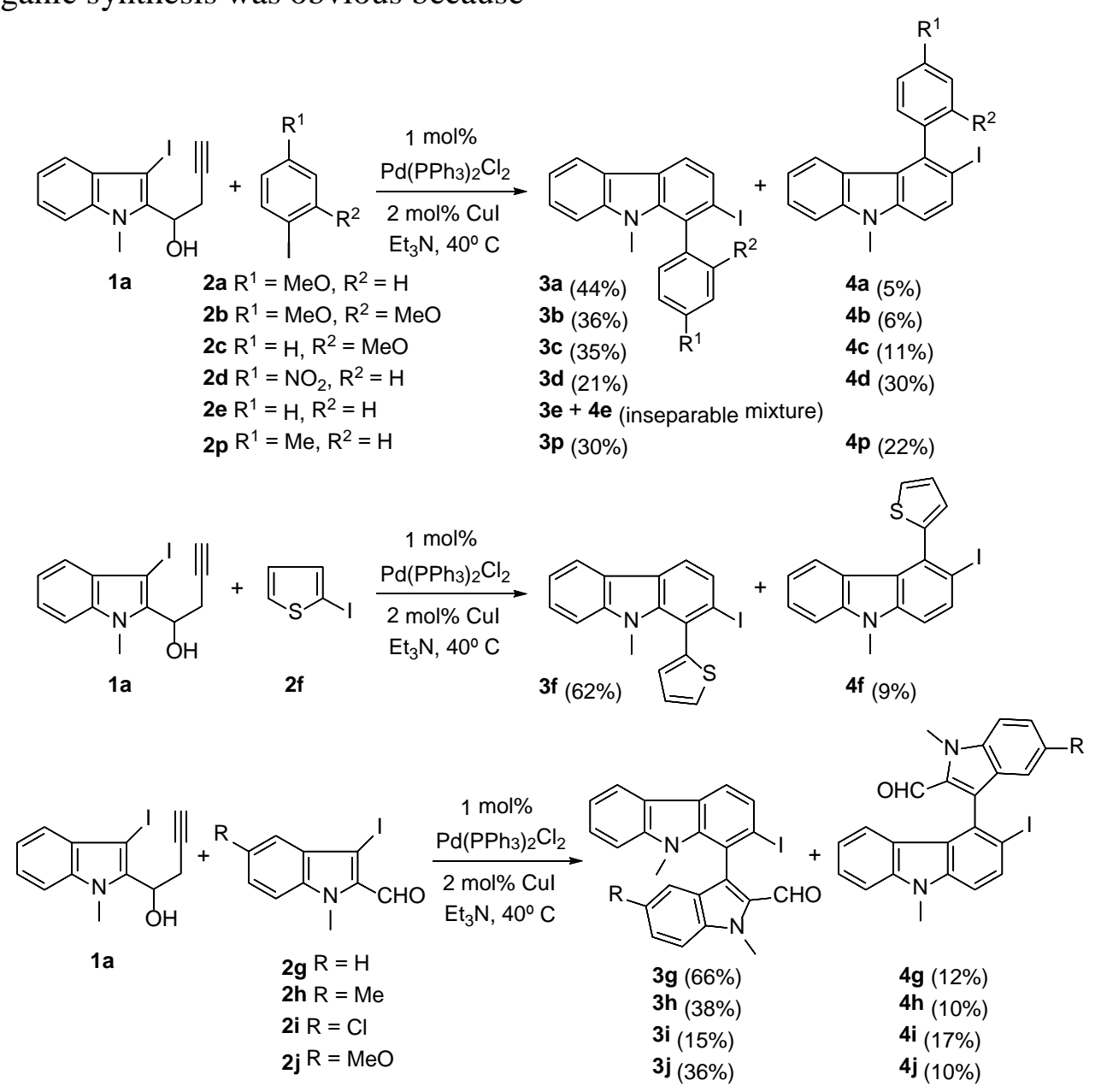

Scheme 2. Controlled preparation of iodocarbazoles 3a-j,p under palladium catalyzed conditions.

Next. the scope of the above transformation was assessed through the reaction between substituted indoles $\mathbf{1}$ and iodoarenes $\mathbf{2}$ (Scheme 3). Emploving the optimized conditions. the preparation of various iodocarbazole derivatives was accomplished starting from 1-(3-iodo- $1 \mathrm{H}$ indol-2-vl)but-3-vn-1-ols $\mathbf{1 b}-\mathbf{d}$ bearing substitution at the benzene ring of the indole nucleus. The cross-coupling/skeletal reorganization seauence was amenable to the presence of neutral or electron-rich benzenoid rings at the indole framework such as in precursors 1a-c. However. but-3-vn-1-ol 1d with a fluorine atom at the indole moietv did react under our conditions to afford the classical Sonogashira product 1da rather than the challenging crosscoupling/carbocyclization/rearrangement/iodine migration adduct. Fortunatelv. bv forcing conditions (heating at $60{ }^{\circ} \mathrm{C}$ ), iodocarbazole 30 could be obtained (Scheme 3). Oxidative addition of the indole $\mathrm{C}-\mathrm{I}$ bond does not occur. Complete conversion was observed, but some dimerization of the starting alkynols $\mathbf{1}$ was detected (Glaser coupling), which may be responsible for the moderate isolated yields of carbazoles 3 and $\mathbf{4}$. An alternative procedure for the formation of 1-aryl2-iodocarbazoles which takes advantage of the iodocyclization reaction between 1-(indol-2yl)but-3-yn-1-ols and electrophilic iodinated reagents has previously been reported. ${ }^{[8]}$ By contrast with our protocol, Liang's group starts from non-iodinated precursors and the iodination arises from an external reagent.

Taking into account the interesting reactivitv of homopropargvl iodoindoles while preserving the svntheticallv valuable iodo functionalitv in the final carbazole products. we decided to take advantage of iodofunctionalized adducts $\mathbf{3}$ and $\mathbf{4}$ for further transformations through Suzuki reaction. Thus. the counling reaction of selected iodocarbazoles 3a.b.d.f and 4a.d.f with (4methoxvphenvl)boronic acid was performed. As shown in Scheme 4. the corresbonding 1.2-diarvlor 3.4-diarvl-carbazoles $\mathbf{5}$ and $\mathbf{6}$ which cannot be easilv predared bv alternative svnthetic routes, were smoothly obtained in fair yields. Heck reaction between iodocarbazole $\mathbf{3 a}$ and styrene 
was also successfully accomplished resulting in 1aryl-2-styryl-carbazole 7.
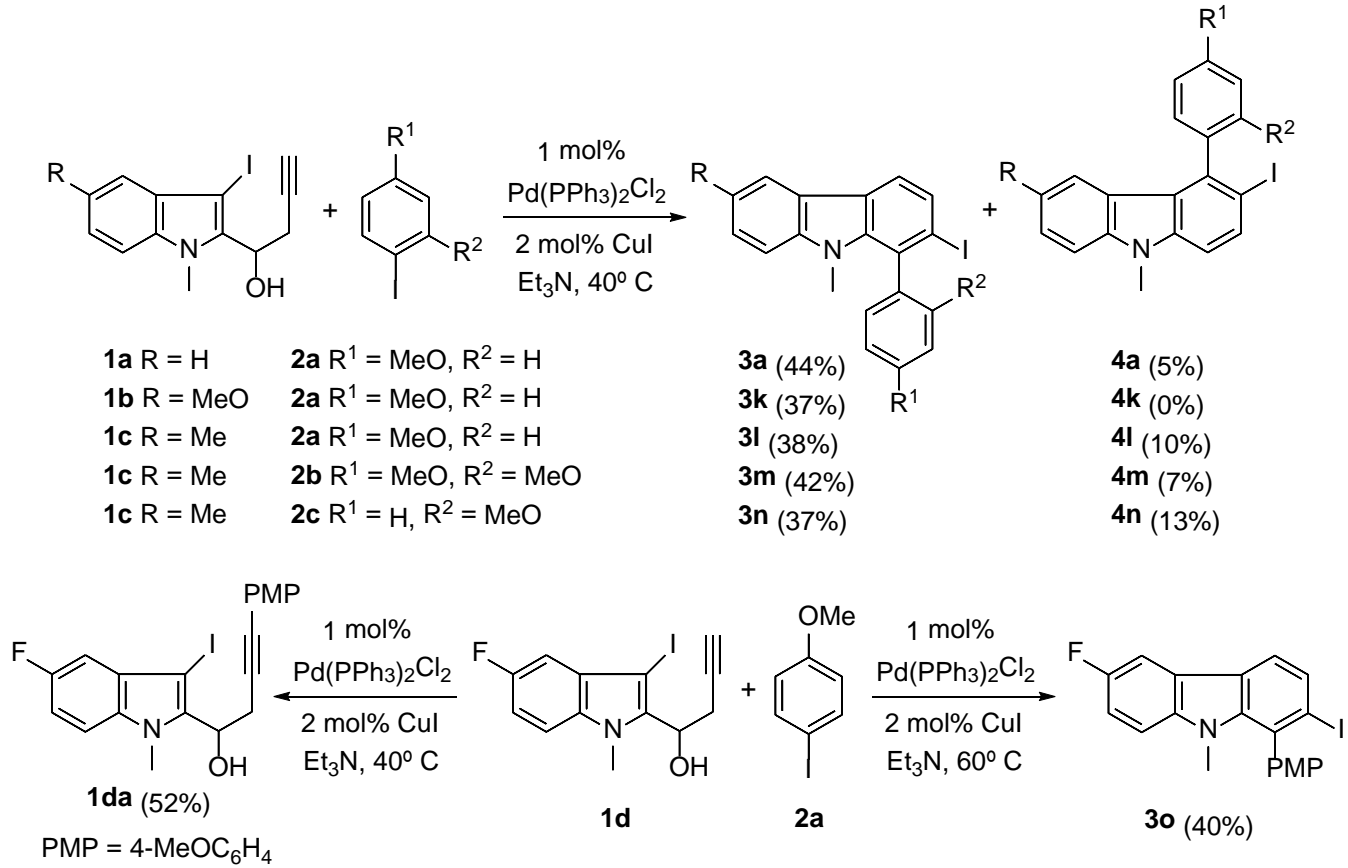

Scheme 3. Controlled preparation of iodocarbazoles 3k-o under palladium-catalyzed conditions.

Bearing in mind the isolation of homoprodagvlic alcohol 1da, we decided to studv the possible isolation of Sonogashira products as putative intermediates for the iodocarbazole formation. Indeed. under otherwise identical reaction conditions for the formation of iodocarbazoles 3 and 4 but after a short reaction time (15 $\mathrm{min})$. the coubling between iodoalkvnol 1a and iodoarene 2a vielded the corresponding Sonogashira adduct 1aa (Scheme 5). We presumed that adducts of tvpe Sonogashira could be transformed into iodocarbazoles. As expected. a further exposure of compound 1aa to the Dalladium-catalvzed conditions generated iodocarbazoles 3a and $\mathbf{4 a}$ in $60 \%$ and $7 \%$ vields. respectivelv (Scheme 5). Consequentlv, it should be concluded that alkvnes substituted at the terminal end are intermediates for the generation of iodocarbazoles. An additional control experiment which consisted in the metal-catalyzed reaction of 1 aa but in the absence of $\mathrm{Pd}\left(\mathrm{PPh}_{3}\right)_{2} \mathrm{Cl}_{2}$ resulted in no formation of the carbazole products while the disappearance of CuI did not affect the reaction, thus disfavoring the Cu-activation scenario in this sted (Scheme 5). Unsurbrisinglv. the reaction of the deuteriumlabeled alkvne [Dl-1a with iodoarene 2a under obtimized conditions resulted in the formation of non-deuterated iodocarbazoles $\mathbf{3 a}$ and $\mathbf{4 a}$ (Scheme 5).

A conceivable iustification that explains the construction of 2-iodocarbazoles $\mathbf{3}$ is debicted in Scheme 6. Sonogashira adducts INT-1 should initiallv be formed under balladium catalvsis from (3-iodoindol-2-vl)butvnols $\mathbf{1}$ and iodoarenes 2 . Thus. the first catalytic cycle is completed. Iodoarenes $\mathbf{2}$ are selectively cross-coupled with alkynols $\mathbf{1}$, but there is no homo-coupling of the alkyne moiety in $\mathbf{1}$ with the heteroaryl iodide of a second molecule of $\mathbf{1}$ probably because of the steric hindrance imbarted bv the butvnol side chain in (3-iodoindol-2-vl)butvnols $\mathbf{1}$. Next. coordination of the Dalladium salt to the alkvne moietv brings about Dalladium comblex INT-1Pd. which provokes further spirocvclization through 5-endo-dia-carbodalladation bv nucleophilic attack of the C2 indole carbon atom. Based on recent DFT studies on related systems which support that the 5-endo-dig path rather than the 6-endo-dig path is kinetically favourable ${ }^{[9]}$ we proposed a 5-endo-dig carbopalladation with the C2 (less nucleophilic position of indole) rather than attack from the 3-position of the indole ring to give 6-endo-dia carbodalladation. ${ }^{[10]}$ The soformed vallada-sbirocvclodentene intermediate INT-2 suffers a chemo- and regioselective 1.2alkvl migration to generate iodotetrahidrocarbazolium species INT-3. Consecutive 1.4-iodonium migration provided 2iodo-1-arvl-4.9-dihvdro-3H-carbazol-4-ols INT4 along with the regeneration of the palladium catalyst in the second catalytic cycle. The direct 1,4-iodonium migration did not probably occur and it may be better described as a formal 1,4iodonium migration composed of several 
consecutive 1,2 shifts, which are thermally allowed and would ultimatelv result in a formal 1.4-I migration. After dehvdration. intermediates INT-4 afforded aromatic 2-iodo carbazole derivatives 3 . The $\mathrm{C}-\mathrm{I}$ bond within the product may be formed by reductive elimination; however taking into account the previous report on the gold-catalvzed svnthesis of iodocarbazoles in which this step is not feasible. ${ }^{[5]}$ we believe that iodine transfer may be operative. The C-I bond within the product may also be formed by initial iodonium lost during the aromatization process and further $\mathrm{C}-\mathrm{Pd}$ bond cleavage, but a related iodine transfer is being supported by DFT in a previous report. ${ }^{[5]}$ We feel that there are not two independent mechanisms (5-endo-dig cyclization for isomer 3 versus 6-endo-dig cyclization for isomer 4) simultaneously operating; we rather think that the mixture of products $\mathbf{3}$ and $\mathbf{4}$ arises from competitive 1,2-migrations (alkyl versus alkenyl), and the formation of INT-3 is favoured by electron-donating aryl groups.<smiles>COc1ccc(-c2c(/C=C/c3ccccc3)ccc3c4ccccc4n(C)c23)cc1</smiles>

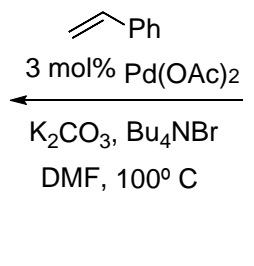<smiles>[R]c1ccc(-c2c(I)ccc3c4ccccc4n(C)c23)c([R])c1</smiles>

3a $\mathrm{R}^{1}=\mathrm{MeO}, \mathrm{R}^{2}=\mathrm{H}$ 3b $\mathrm{R}^{1}=\mathrm{MeO}, \mathrm{R}^{2}=\mathrm{MeO}$ 3d $\mathrm{R}^{1}=\mathrm{NO}_{2}, \mathrm{R}^{2}=\mathrm{H}$
$\operatorname{ArB}(\mathrm{OH})_{2}$

5 mol\% $\mathrm{Pd}(\mathrm{PPh} 3) 4$ $\mathrm{K}_{2} \mathrm{CO}_{3}$

1,4-dioxane: $\mathrm{H}_{2} \mathrm{O}(5: 1)$ $80^{\circ} \mathrm{C}$

$\mathrm{Ar}=4-\mathrm{MeOC}_{6} \mathrm{H}_{4}$<smiles>[R]c1ccc(-c2c([Al])ccc3c2c2ccccc2n3C)c([R])c1</smiles>

$5 a(64 \%)$

$5 \mathbf{b}(83 \%)$

5d $(30 \%)$
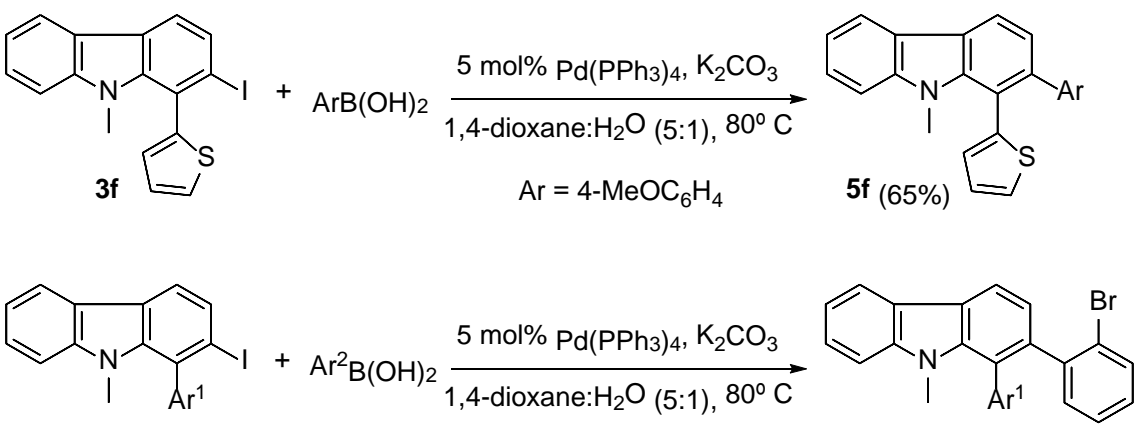

3a $\mathrm{Ar}^{1}=4-\mathrm{MeOC}_{6} \mathrm{H}_{4}$

$\mathrm{Ar}^{2}=2-\mathrm{BrC}_{6} \mathrm{H}_{4}$

$5 a-B r(98 \%)$<smiles>[R]c1ccc(-c2c(I)ccc3c2c2ccccc2n3C)cc1</smiles>

$4 \mathrm{a} \mathrm{R}^{1}=\mathrm{MeO}$

$4 d R^{1}=\mathrm{NO}_{2}$

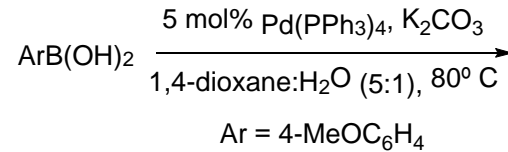<smiles>[R1]c1ccc(-c2c(Br)ccc3c2c2ccccc2n3C)cc1</smiles>

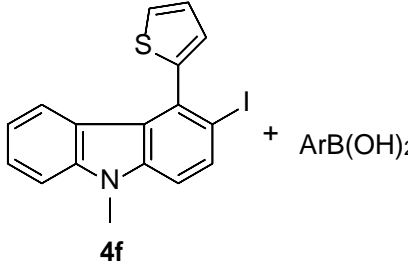

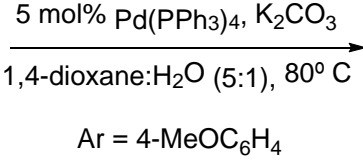<smiles>[13O]n1c2ccccc2c2c(Br)c(Br)ccc21</smiles>

Scheme 4. Synthesis of 1,2(3,4)-diaryl-9H-carbazoles 5,6 and 1-aryl-2-styryl-carbazole 7 under Suzuki or Heck reaction conditions. 

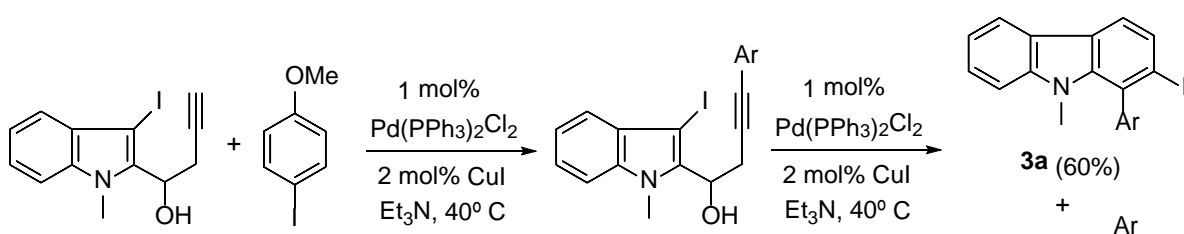

$3 a$ (60\%)

$1 a$

$2 a$

$15 \mathrm{~min}$

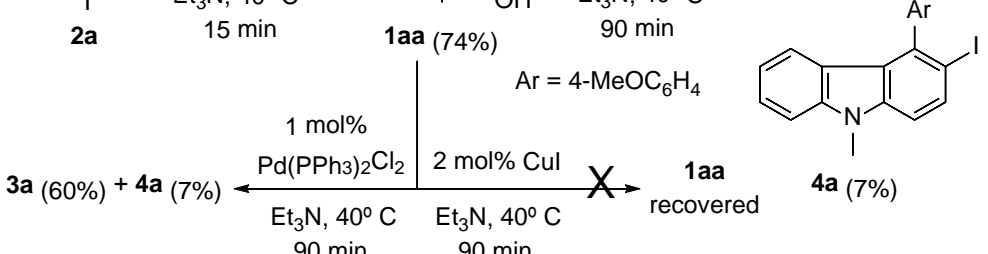

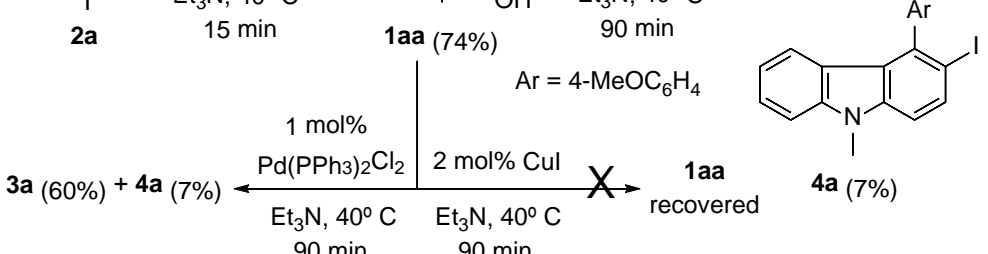

$90 \mathrm{~min} \quad 90 \mathrm{~min}$

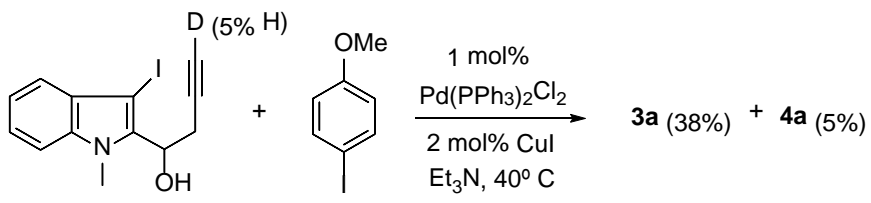

[D]-1a

$2 a$

Scheme 5. Control experiments.
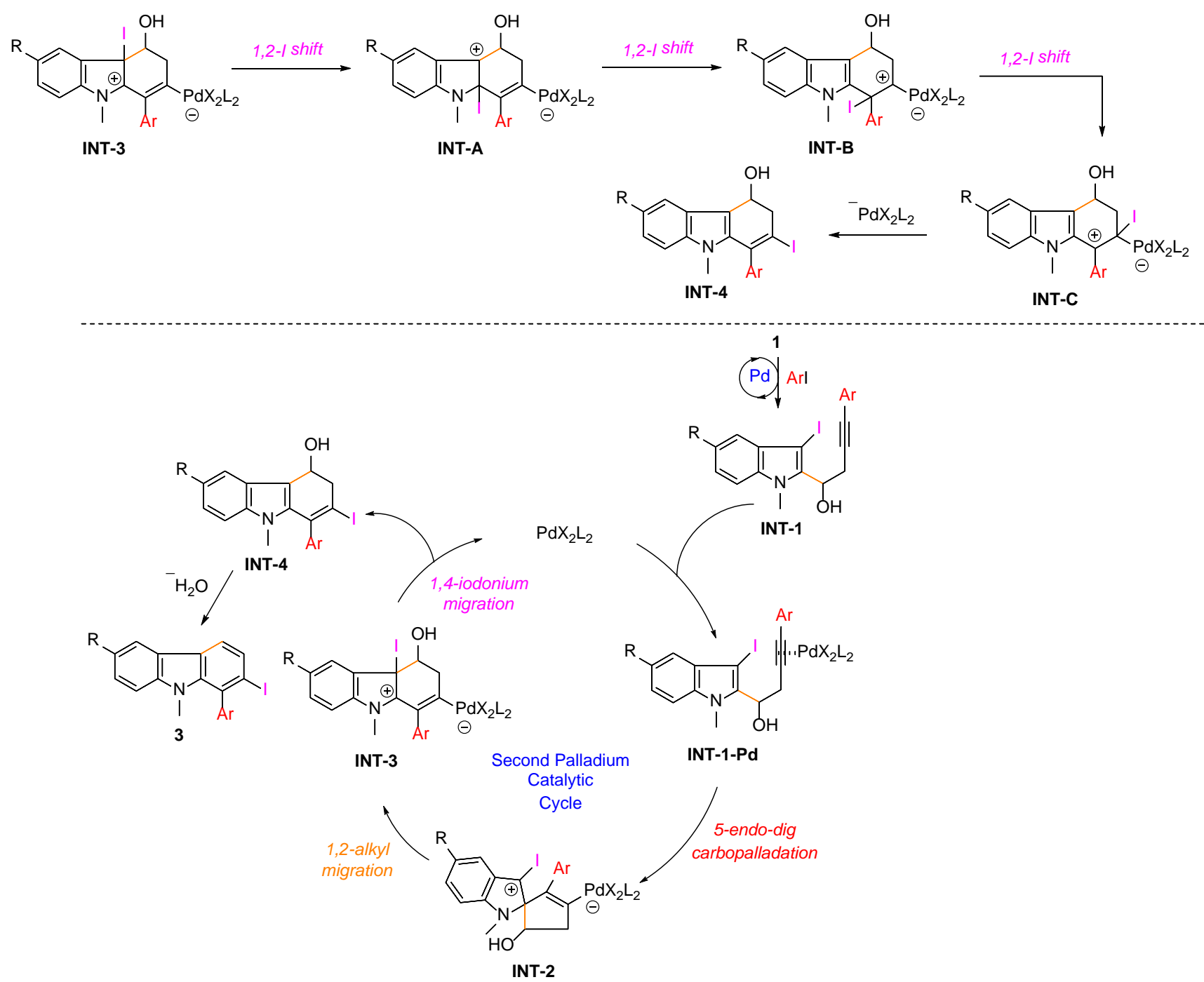

Scheme 6. Feasible pathway for the palladium-catalyzed preparation of 2-iodocarbazoles $\mathbf{3}$ from yodoindoles $\mathbf{1}$. 
In summarv, a novel approach to build 2-iodo-1arvl-9H-carbazoles through a convenient Pdcatalvzed $\mathrm{C}(\mathrm{sp})-\mathrm{H}$ arvlation/carbocvclization/iodonium migration domino reaction has been developed. This protocol reveals that Dalladium not onlv can conduct the Sonogashira reaction on terminal (indol-2-vl)butvnols but also provides distinct selectivitv compared with gold. This seauence is complementarv to the Au-catalvzed process. as we possess now a divergent strategv to form each isomer of the carbazole products. namelv 2-iodo1-arvl-9H-carbazoles and 3-iodo-4-arvl-9Hcarbazoles. ${ }^{[11]}$ with high selectivitv. The formation of these iodocarbazoles is also of interest because the arvl iodide moietv of the soobtained iodocarbazoles can be further functionalized via Suzuki cross-coupling.

\section{Experimental Section}

Typical Procedure for the Palladium-Catalyzed Reaction of 1-(3-iodo-1-methyl-1H-indol-2-yl)but-3-yn1-ols; Synthesis of 2-iodo-1-aryl-9H-carbazoles $3 a / 4 a$.

A solution of alkynol 1 (50 mg, 0.154 mmol) in $\mathrm{Et}_{3} \mathrm{~N}(0.22$ $\mathrm{mL}, 1.54 \mathrm{mmol}$ ) was added dropwise to a stirred solution of 4-iodoanisole (40 mg, $0.169 \mathrm{mmol})$, CuI (0.6 mg, 0.00308 mmol) and $\mathrm{PdCl}_{2}\left(\mathrm{PPh}_{3}\right)_{2}(1 \mathrm{mg}, 0.00154 \mathrm{mmol})$ in $\mathrm{Et}_{3} \mathrm{~N}$ (0.39 $\mathrm{mL}, 2.8 \mathrm{mmol})$ at room temperature. Then, the reaction was heated at $40^{\circ} \mathrm{C}$ after disappearance of the starting material (TLC). The mixture was washed with $\mathrm{NH}_{4} \mathrm{Cl}(3 \times 20 \mathrm{~mL})$ and extracted with ethyl acetate $(3 \times 20$ $\mathrm{mL})$. The organic extract was washed with brine $(2 \times 15 \mathrm{~mL})$, dried $\left(\mathrm{MgSO}_{4}\right)$ and concentrated under reduced pressure. A mixture of two carbazoles in a ratio (90:10) was obtained. After chromatography of the residue using $n$-hexane/ethyl acetate (9:1) as eluent, a less polar compound 3a (28 mg, $44 \%)$ and a more polar compound $4 a(3 \mathrm{mg}, 5 \%)$ were obtained. Iodocarbazole 3a. Colorless oil; ${ }^{1} \mathrm{H}$ NMR (300 $\left.\mathrm{MHz} \mathrm{CDCl}_{3}, 25^{\circ} \mathrm{C}\right) \delta: 8.10(1 \mathrm{H}, \mathrm{d}, J=7.7 \mathrm{~Hz}, \mathrm{H} \mathrm{Ar}), 7.79$ (2H, s, H Ar), 7.49 (1H, ddd, $J=8.3,7.2,1.1 \mathrm{~Hz}, \mathrm{H}$ Ar), 7.32-7.23 (4H, m + AA'XX', H Ar +2 CH Ar PMP), 7.067.03 (2H, AA' $X X^{\prime}, 2$ CH Ar PMP), 3.93 (3H, s, O-CH ${ }_{3}$ ), $3.19\left(3 \mathrm{H}, \mathrm{s}, \mathrm{N}-\mathrm{CH}_{3}\right) ;{ }^{13} \mathrm{C} \mathrm{NMR}\left(75 \mathrm{MHz}, \mathrm{CDCl}_{3}, 25^{\circ} \mathrm{C}\right)$ 159.5 (C Ar), 141.5 (C Ar), 139.0 (C Ar), 134.9 (C Ar), 131.9 (2 x CH Ar), 129.3 (C Ar), 129.2 (CH Ar), 126.3 (CH $\mathrm{Ar}), 123.6$ (C Ar), 122.1 (C Ar), 120.6 (CH Ar), 120.0 (CH $\mathrm{Ar}), 119.4$ (CH Ar), 113.5 (2 x CAr), 108.9 (CH Ar), 100.2 (C Ar), $55.3\left(\mathrm{O}-\mathrm{CH}_{3}\right), 32.0\left(\mathrm{~N}-\mathrm{CH}_{3}\right) ; \mathrm{IR}\left(\mathrm{CDCl}_{3}, \mathrm{Cm}^{-1}\right): \mathrm{v}$ 2926 (Ar, C-H), $2853\left(\mathrm{O}-\mathrm{CH}_{3}\right), 1512$ (Ar), 1245 (Ar); HRMS (ES): calcd for $\mathrm{C}_{20} \mathrm{H}_{17} \mathrm{INO}[M+\mathrm{H}]^{+}$: 414.03493 ; found: 414.03413. Iodocarbazole 4a. Colorless oil; ${ }^{1} \mathrm{H}$ NMR $\left(700 \mathrm{MHz}, \mathrm{CDCl}_{3}, 25^{\circ} \mathrm{C}\right) \delta: 7.98(1 \mathrm{H}, \mathrm{d}, J=8.5 \mathrm{~Hz}$, HAr), 7.42-7.39 (1H, m, HAr), $7.37(1 \mathrm{H}, \mathrm{d}, J=8.1 \mathrm{~Hz}, \mathrm{HAr})$, 7.28-7.27 (2H, AA'XX', 2 CHArPMP), $7.18(1 \mathrm{H}, \mathrm{d}, J=8.6$ $\mathrm{Hz}, \mathrm{HAr}), 7.12-7.11$ (2H, AA' $X X^{\prime}, 2 \mathrm{CH}$ Ar PMP), $6.95(1 \mathrm{H}$, ddd, $J=8.1,6.5,1.7 \mathrm{~Hz}, \mathrm{HAr}), 6.78(1 \mathrm{H}, \mathrm{d}, J=8.0 \mathrm{~Hz}$, $\mathrm{HAr}), 3.96\left(3 \mathrm{H}, \mathrm{s}, \mathrm{O}-\mathrm{CH}_{3}\right), 3.87\left(3 \mathrm{H}, \mathrm{s}, \mathrm{N}-\mathrm{CH}_{3}\right) ;{ }^{13} \mathrm{C} \mathrm{NMR}$ $\left(175 \mathrm{MHz}, \mathrm{CDCl}_{3}, 2^{\circ} \mathrm{C}\right)$ $\delta: 159.3$ (CAr), 140.9 (CAr), 140.8 (CAr), 140.7 (CAr), 135.0 (CHAr), 130.4 (2xCHAr), 126.0 (CHAr), 122.8 (CAr), 122.4 (CHAr), 122.2 (CAr), 119.1 (CHAr), 114.1 (2xCHAr), 109.4 (CHAr), 108.2 (CHAr), 89.3 (CAr), $55.3\left(\mathrm{O}-\mathrm{CH}_{3}\right), 29.2\left(\mathrm{~N}-\mathrm{CH}_{3}\right)$; IR $\left(\mathrm{CDCl}_{3}, \mathrm{~cm}^{-1}\right)$ v: 2924 (Ar, C-H), $2853\left(\mathrm{O}-\mathrm{CH}_{3}\right), 1243(\mathrm{Ar})$.

Supporting Information Available: Experimental procedures, characterization data of new compounds, and copies of NMR spectra. This material is available free of charge on the ACS Publication website at DOI: .

\section{Acknowledgements}

Acknowledgment. This work was supported in part by AEI (MICIU) and FEDER (Project PGC2018-095025-B-I00). I. M. thanks MICIU for a predoctoral contract.

\section{References}

[1] For reviews, see: a) T.-Y. Shang, L.-H. Lu, Z. Cao, Y. Liu, W.-M. He, B. Yu, Chem. Commun. 2019, 55, 54085419; b) A. W. Schmidt, K. R. Reddy, H.-J. Knölker, Chem. Rev. 2012, 112, 3193-3328; c) H. J. Jiang, J. Sun, J. L. Zhang, Curr. Org. Chem. 2012, 16, 2014-2025; d) J. Roy, A. K. Jana, D. Mal, Tetrahedron 2012, 68, 60996121; e) J. Li, A. G. Grimsdale, Chem. Soc. Rev. 2010, 39, 2399-2410; f) H.-J. Knölker, K. R. Reddy, Chem. Rev. 2002, 102, 4303-4427; g) M. Li, Chem. Eur. J. 2019, 25, 1142-1151.

[2] a) N. Hazari, N, P.R. Melvin, M.M. Beromi, M. M. Nat. Rev. Chem. 2017, 1, Article number: 0025; b) P. RuizCastillo, S. L. Buchwald, Chem. Rev. 2016, 116, 12564 12649; c) H. Li, C. C. C. J. Seechurn; T. J. Colacot, ACS Catal. 2012, 2, 1147-1164; d) J. Magano, J. R. Dunetz, Chem. Rev. 2011, 111, 2177-2250; e) Cross Coupling Reactions in Organic Synthesis (issue 10, themed collection; Ed.: M. Beller): Chem. Soc. Rev. 2011, 40, 4879-5203; f) K. C. Nicolaou, P. G. Bulger, D. Sarlah, Angew. Chem. 2005, 117, 4516-4563; Angew. Chem. Int. Ed. 2005, 44, 4442-4489.

[3] a) Z.-M. Zhang, B. Xu, L. Wu, L. Zhou, D. Ji, Y. Liu, Z. Li, J. Zhang, J. Am. Chem. Soc. 2019, 141, 8110-8115; b) A. D. Marchese, F. Lind, A. E. Mahon, H. Yoon, M. Lautens, Angew. Chem. 2019, 131, 5149-5153; Angew. Chem. Int. Ed. 2019, 58, 5095-5099; c) Y. H. Lee, B. Morandi, Angew. Chem. 2019, 131, 6510-6515; Angew. Chem. Int. Ed. 2019, 58, 6444-6448; d) M. Murai, K. Takai, Org. Lett. 2019, 21, 6756-6760; e) Y.-L. Sun, X.B. Wang, F.-N. Sun, Q.-Q. Chen, J. Cao, Z. Xu, L.-W. $\mathrm{Xu}$, Angew. Chem. 2019, 131, 6819-6823; Angew. Chem. Int. Ed. 2019, 58, 6747-6751; f) P. FernándezCanelas, E. Rubio, J. M. González, Org. Lett. 2019, 21, 6566-6569; g) H. Yoon, A. D. Marchese, M. Lautens, J. Am. Chem. Soc. 2018, 140, 10950-10954; h) C. M. Le, P. J. C. Menzies, D. A. Petrone, M. Lautens, Angew. Chem. 2015, 127, 256-259; Angew. Chem. Int. Ed. 2015, 54, 254-257; i) P. Nösel, V. Müller, S. Mader, S. Moghimi, M. Rudolph, I. Braun, F. Rominger, A. S. K. Hashmi, Adv. Synth. Catal. 2015, 357, 500-506; j) P. Morán-Poladura, E. Rubio, J. M. González, Angew. Chem. 2015, 127, 3095-3098; Angew. Chem. Int. Ed. 2015, 54, 3052-3055; k) S. Mader, L. Molinari, M, Rudolph, F. Rominger, A. S. K. Hashmi, Chem. Eur. J. 2015, 21, 3910-3913; l) B. M. Monks, S. P. Cook, Angew. Chem. 2013, 125, 14464-14468; Angew. Chem. Int. Ed. 2013, 52, 14214-14218; m) D. A. Petrone, M. Lischka, M. Lautens, Angew. Chem. 2013, 125, 
10829-10832; Angew. Chem. Int. Ed. 2013, 52, 1063510638; n) P. Nösel, T, Lauterbach, M. Rudolph, F. Rominger, A. S. K. Hashmi, Chem. Eur. J. 2013, 19, 8634-8641; o) R. D. Grigg, R. Van Hoveln, J. M. Schomaker, J. Am. Chem. Soc. 2012, 134, 1613116134; p) S. G. Newman, M. Lautens, J. Am. Chem. Soc. 2011, 133, 1778-1780. For a review on the carbohalofunctionalization reactions of multiple bonds, see: q) D. Bag, S. Mahajan, S. D. Sawant, Adv. Synth. Catal. 2020, 362, 3948-3970.

[4] a) A. S. K. Hashmi, W. Yang, F. Rominger, Chem. Eur. J. 2012, 18, 6576-6580; b) Y. Qiu, W. Kong, C. Fu, S. Ma, Org. Lett. 2012, 14, 6198-6201.

[5] B. Alcaide, P. Almendros, J. Alonso, E. Busto, I. Fernández, M. P. Ruiz, G. Xiaokaiti, ACS Catal. 2015, 5, 3417-3421.

[6] For the iodination of the carbazole nucleus and the importance of halogenated carbazoles as precursors of bioactive compounds and advanced materials, see: a) J. R. Dobscha, H. D. Castillo, Y. Li, R. E. Fadler, R. D. Taylor, A. A. Brown, C. Q. Trainor, S. L. Tait, A. H. Flood, J. Am. Chem. Soc. 2019, 141, 17588-17600; b) M. H. Ghom, M. S. Naykode, V. T. Humne, P. D. Lokhande, Tetrahedron Lett. 2019, 60, 1029-1031 and references therein; c) L. Przypis, K. Z. Walczak, J. Org. Chem. 2019, 84, 2287-2296 and references therein.
[7] a) A. S. K. Hashmi, Chem. Rev. 2007, 107, 3180-3211; b) D. Pflästerer, A. S. K. Hashmi, Chem. Soc. Rev. 2016, 45, 1331-1367.

[8] J. Wang, H.-T. Zhu, Y.-F. Qiu, Y. Niu, S. Chen, Y.-X. Li, X.-Y. Liu, Y.-M. Liang, Org. Lett. 2015, 17, 31863189.

[9] a) B. Cheng, G. Huang, L. Xu and Y. Xia Org. Biomol. Chem. 2012, 10, 4417; b) I. Martín-Mejías, C. Aragoncillo, H. Yanai, S. Hoshikawa, Y. Fujimoto, T. Matsumoto and P. Almendros Chem. Commun. 2020, 56, 1795.

[10] Besides, the direct 6-endo-dig carbopalladation could only explain the formation of minor carbazole isomers 4 but not major rearranged isomers 3.

[11] 2D NMR spectra and NOE experiments allowed the unequivocal identification of isomeric carbazoles $\mathbf{3}$ and 4. It should be noted that the relative ${ }^{1} \mathrm{H}$ NMR chemical shift of the $\mathrm{N}-\mathrm{CH}_{3}$ protons for the $\mathbf{3}$ and $\mathbf{4}$ iodocarbazoles is a useful check of the regiochemistry; for any pair of $\mathbf{3}$ and 4 isomers, the $\mathrm{N}-\mathrm{CH}_{3}$ hydrogens of 3iodocarbazoles 4 were approximately $0.4-0-7 \mathrm{ppm}$ downfield of the analogous hydrogens of 2iodocarbazoles 3 . 


\section{UPDATE}

Palladium-Catalyzed Hydroarylation of Homopropargyl Iodoindoles with Concurrent Alkyl and Iodonium Migrations

Adv. Synth. Catal. Year, Volume, Page - Page

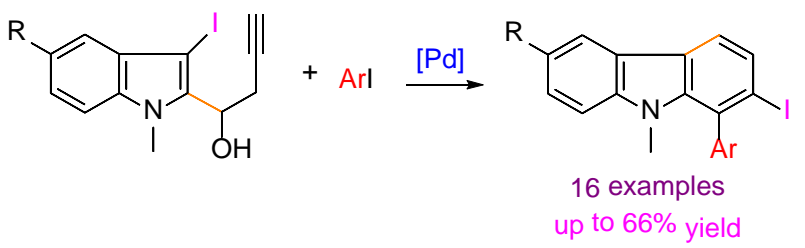

Irene Martín, ${ }^{\mathrm{a}}$ Cristina Aragoncillo, ${ }^{\mathrm{b} *}$ and Pedro Almendros ${ }^{\text {a* }}$

Autores: Martín-Mejías, I.; Aragoncillo, C.; Almendros, P.

Título: Palladium-Catalyzed Hydroarylation of Homopropargyl Iodoindoles with Concurrent Alkyl and Iodonium Migrations

Revista: Adv. Synth. Catal. 2021, 363, 1449-1456; DOI: 10.1002/adsc.202001267 